\title{
Afferents contributing to the exaggerated long latency reflex response to electrical stimulation in Parkinson's disease
}

\author{
J P HUNTER, P ASHBY, A E LANG \\ From the Playfair Neuroscience Unit, University of Toronto, Toronto Western Hospital, Toronto, Ontario, \\ Canada
}

SUMMARY Reflex pathways to tibialis anterior motoneurons from low threshold afferents of the common peroneal nerve were examined in 13 Parkinsonian subjects and 12 age-matched normals. Post-synaptic events occurring in single motoneurons were derived from changes in the firing probability of single voluntarily activated motor units during afferent stimulation. A period of increased firing probability of "monosynaptic" latency (about $33 \mathrm{~ms}$ ) occurred in all subjects in both groups. A second, later, period of increased firing probability (latency about $64 \mathrm{~ms}$ ) was seen in 2/12 normals and 8/13 Parkinsonian subjects. Neither of these responses could be produced by cutaneous stimulation. The electrical threshold of the afferents mediating the later effect was 0.82 of the threshold of alpha motoneuron axons which is similar to that of the afferents mediating the shorter latency response. Thus, large non cutaneous afferents contribute to this long latency response in man presumably through polysynaptic pathways. Transmission in these pathways is enhanced in Parkinson's disease.

Perturbations of a limb in man can cause segmented reflex responses in the stretched muscles. ${ }^{1}$ The reflex response with the shortest latency, labelled M1 by Lee and Tatton, ${ }^{2}$ is attributed to the predominantly "monosynaptic" facilitation of motoneurons from primary spindle endings. ${ }^{3}$ A longer latency response, labelled M2 by Lee and Tatton, ${ }^{2}$ has a number of possible explanations which include two opposing theories; first, that the response is mediated by large, fast conducting afferents to the spinal cord and then by polysynaptic, and possibly "long loop" pathways to motoneurons, the main delay being in the central nervous system; ${ }^{4-7}$ second, that the response is mediated by slowly conducting afferents to the spinal cord then by oligosynaptic pathways to motoneurons the main delay being in the peripheral nervous system. ${ }^{89}$ These two possibilities cannot be distinguished by limb perturbation since this stimulus excites many

Address for reprint requests: Dr Peter Ashby, Playfair Neuroscience Unit, Toronto Western Hospital, 399 Bathurst Street, Toronto, Ontario, Canada M5T 258.

Received 9 February 1988 and in revised form 4 May 1988. Accepted 13 May 1988 different receptors whose afferents have different conduction velocities. Electrical stimulation of a peripheral nerve however, excites axons in approximate relation to their size, the larger axons having lower thresholds. $^{1011}$ If long latency responses could be elicited by electrical stimulation of low threshold afferents in peripheral nerves then polysynaptic pathways from these afferents must exist and these pathways might contribute to the late responses produced by stretch. To test for this possibility we examined the reflex effects produced in tibialis anterior motoneurons by electrical stimulation of low threshold afferents in the peroneal nerve in normal subjects.

In Parkinson's disease the long latency response (M2) to limb perturbation is exaggerated. ${ }^{212-19} \mathrm{We}$ also examined patients with Parkinson's disease to determine whether any long latency responses obtained from electrical stimulation of low theshold afferents were exaggerated in these patients.

Methods

Observations were made on 12 normal subjects aged 32 to 83 years $($ mean $=57 \cdot 8)$ and 13 patients with Parkinson's disease 
aged 39 to 69 years $($ mean $=55 \cdot 8)$. Patients with Parkinson's disease with bradykinesia and/or rigidity in the lower extremities, but little or no tremor, were asked to volunteer for the study and provided informed consent. Rigidity was graded on a scale of $0-4$ for each limb and for the trunk, making the total possiblle score for the four limbs and trunk between 0 and 20 . The patients were classified as "mild" if the rigidity score of the tested limb was zero and the tota score was less than 4 , and "moderate" if the rigidity score for the tested limb was one or more or the total score was 4 or more.

The common peroneal nerve was stimulated with surface electrodes $(2.5 \mathrm{~cm}$ apart) at the head of the fibula using square wave stimuli $0.5 \mathrm{~ms}$ in duration, delivered at $303 \mathrm{~ms}$ intervals. The electrode was carefully positioned to stimulate the alpha motoneuron axons innervating the tibialis anterior at a lower voltage than that required to stimulate the alpha motoneuron axons innervating the peroneus longus muscle. The motor threshold (MT) for a given muscle was determined by gradually increasing the stimulus voltage until the first alpha motoneuron axons to that muscle were activated, as judged by a movement of the muscle tendon and/or an action potential on the surface EMG recording (surface EMG was monitored using pairs of surface electrodes placed $4 \mathrm{~cm}$ apart over the tibialis anterior and peroneus longus muscles). Stimulus strength was expressed in multiples of this MT voltage. Local cutaneous afferents in the region of the knee were stimulated by moving the stimulating electrode from its position over the peroneal nerve to neighbouring sites. Cutaneous afferents in the distribution of the peroneal nerve were activated by stimulating the distal peroneal nerve at the ankle and by stimulating the toes

To record motor unit activity, a concentric needle electrode (cross sectional area $=0.65 \mathrm{~mm}^{2}$, central electrode surface area $=0.07 \mathrm{~mm}^{2}$ ) was inserted into the tibialis anterior muscle $10 \mathrm{~cm}$ below the tibial tuberosity and $1 \mathrm{~cm}$ latera to the tibial crest, and positioned close to a motor unit activated by gentle voluntary contraction. The signal was amplified 5000-10000 times and filtered using a band pass of $10 \mathrm{~Hz}$ to $30 \mathrm{kHz}$. A window discriminator and peak detector were used to select a given motor unit action potential. The subject was provided with auditory and visual feedback of the motor unit discharges, and was instructed to keep the unit discharging at a constant rate. Peristimulus time histograms (nth order) with $400 \mu \mathrm{s}$ bins (a $30 \mathrm{~ms}$ prestimulus period and a $170 \mathrm{~ms}$ poststimulus period) of the occurrences of the single motor unit's action potentials in response to more than 2000 stimuli were generated using a lab computer. A five bin running average was used prior to the analysis to reduce bin to bin variation. The thresholds for detection of a response (see below) were established from unsmoothed histograms to permit the comparison with previous data.

The mean background firing probability of the motor unit was calculated from the $30 \mathrm{~ms}$ prestimulus period. A period of increased firing probability was accepted if the firing probability in three or more adjacent bins exceeded the mean background firing probability plus 2 standard deviations.

A "satisfactory recording" was defined as a run in which a motor unit's spike train had been recorded without contamination from other motor units or artifact during the delivery of more than 2000 stimuli. The "threshold" for detection of a facilitatory effect was determined in the fol- lowing way. Consecutive recordings of the same motor unit were obtained using different stimulus intensities until "satisfactory recordings" above and below the stimulus intensity required for the observed effect were obtained (with a stimulus separation of not more than 0.05 MT). Paired stimuli (5 ms apart and of equal intensity) were used to ensure that small late responses were not overlooked when searching for the threshold for detection of the long latency response. The rise time of the motor unit action potential was subtracted from the response latency to obtain the actual or "corrected" latency (for further details of the method see Mao et $a l^{20}$ ).

All experiments were recorded on magnetic tape for further analyses. First order peristimulus histograms, which record only the first time a unit fires in relation to a stimulus, were also constructed from these tapes to exclude double discharges of motor units.

Student's $t$ test and Chi-square analysis were used for statistical analysis. Probabilities of less than 0.05 (two-tailed) were considered to be significant.

\section{Results}

In the normal subjects (fig 1, top histogram), all of the units studied (49 units in 12 subjects) had a short latency period of increased firing probability which will be referred to as the "short latency response". The mean corrected latency was $33.1 \mathrm{~ms}(\mathrm{SD}=2.3 \mathrm{~ms})$. A second, longer latency response was also seen in two of the 12 normal subjects. The mean corrected latency was $65 \mathrm{~ms}(\mathrm{SD}=3.24 \mathrm{~ms}$ ).

In the Parkinsonian patients (fig 1, bottom histogram) all except one of the units given an adequate

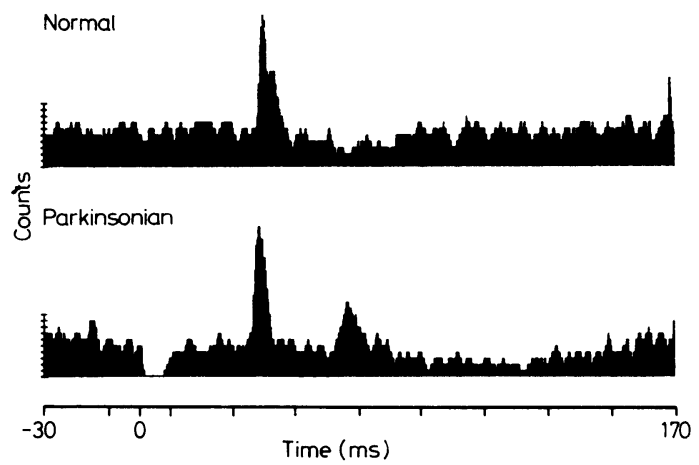

Fig 1 Peristimulus time histograms (PSTH) of a tibialis anterior motor unit in a normal subject (top) and a Parkinsonian subject (bottom) during stimulation of the deep peroneal nerve (at time zero) at an intensity of $0.9 \times$ the threshold of the alpha motor neuron axons $(0.9 \mathrm{MT})$. Bin width $=400 \mu \mathrm{s}$. The histograms have been smoothed using a five bin running average. Vertical scale indicates the number of counts in each bin. Note the short latency period of increased firing probability in both histograms at about $40 \mathrm{~ms}$, and, the additional longer latency peak in the bottom histogram at about $68 \mathrm{~ms}$. The gap near time zero in the bottom histogram results from stimulus artifacts. 

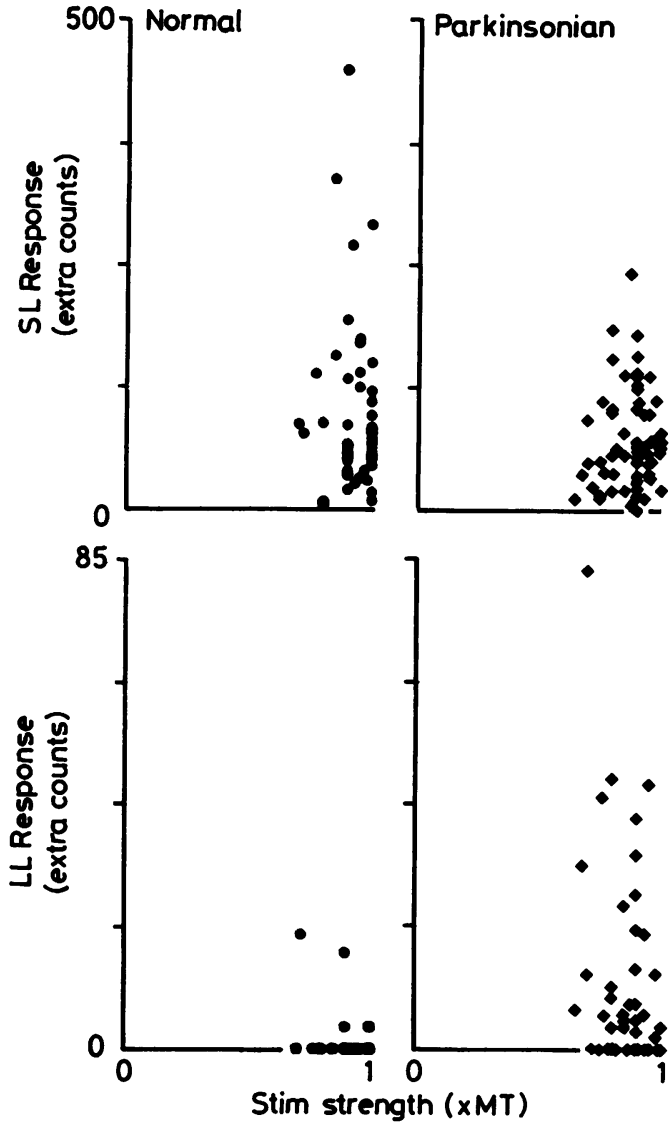

Fig 2 A comparison of the effectiveness of the short and long latency facilitation of tibialis anterior motor units produced by stimulation of the deep peroneal nerve in normal subjects (left), and Parkinsonian subjects (right). Abscissa: stimulation intensity expressed in terms of the threshold of the alpha motoneuron axons (MT). Ordinate the number of extra counts normalised to 1,000 stimuli in the short latency period of increased firing probability (short latency response) (top) and in the longer latency response (bottom).

trial (that is with stimulus strengths as high as $1 \mathrm{MT}$ before the run was classified as negative) had a short latency response (61/62 units 13 subjects). The mean corrected latency was $32.7 \mathrm{~ms}(\mathrm{SD}=5.1 \mathrm{~ms})$. The responses were similar in magnitude (in extra counts per 1000 sweeps) to those of the normal subjects $(t=$ $1.91 \mathrm{p}>0.05$ ) (fig 2). Long latency responses occurred in eight of the 13 Parkinsonian subjects (fig 2 ), which is a significantly greater proportion than for normal subjects (Chi-square $=5.23 ; \mathrm{p}<0.025)$. The mean corrected latency was $61.3 \mathrm{~ms}(\mathrm{SD}=5.1 \mathrm{~ms})$. The mean of the differences in latency between the short and the long latency responses in Parkinsonian subjects was $25 \mathrm{~ms}$. A long latency response was seen in seven of eight patients with moderate rigidity but in only one of the five patients with mild rigidity. The thresholds of the axons mediating the long latency response were established in six Parkinsonian subjects. Paired stimulation (see Methods) was used in two of these studies (fig 3). The mean threshold of the long latency response was $0.82 \times$ MT (range $0.675-0.85 \mathrm{MT}$ ). This is similar to the mean threshold for the axons mediating the short latency response in this muscle (mean 0.79 MT, range 0.76-0.85 MT) established in this laboratory. ${ }^{20}$ The possibility that cutaneous afferents contributed to the late responses was excluded by additional studies on a normal subject and on the Parkinsonian subject who showed the largest late responses. Long latency responses could not be elicited by stimulating the skin near the head of the fibula. Stimulation of the deep peroneal nerve at the ankle (at an intensity just below motor threshold to extensor digitorum brevis muscle) produced only

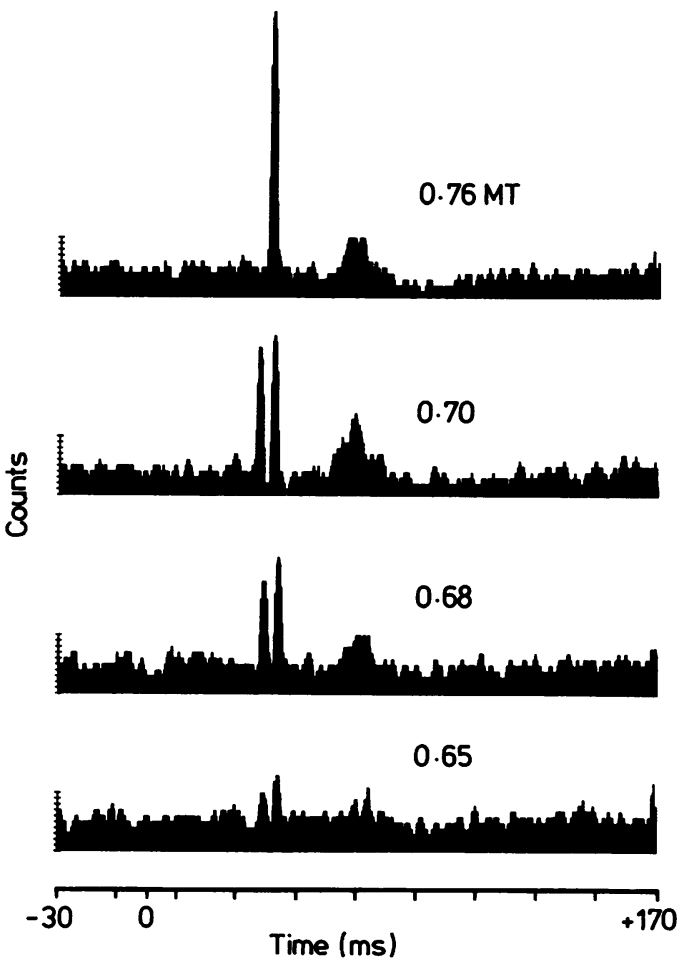

Fig 3 PSTHs of a tibialis anterior motor unit in a Parkinsonian subject during stimulation of the deep peroneal nerve at (top down) $0.76,0.7,0.68,0.65 \times M T$. Paired stimuli ( $5 \mathrm{~ms}$ apart) were used in the lower three recordings. A long latency period of increased firing probability (long latency response) was observed with a "threshold" (see Methods) less than 0.65 MT., which is similar to the threshold for the short response. 


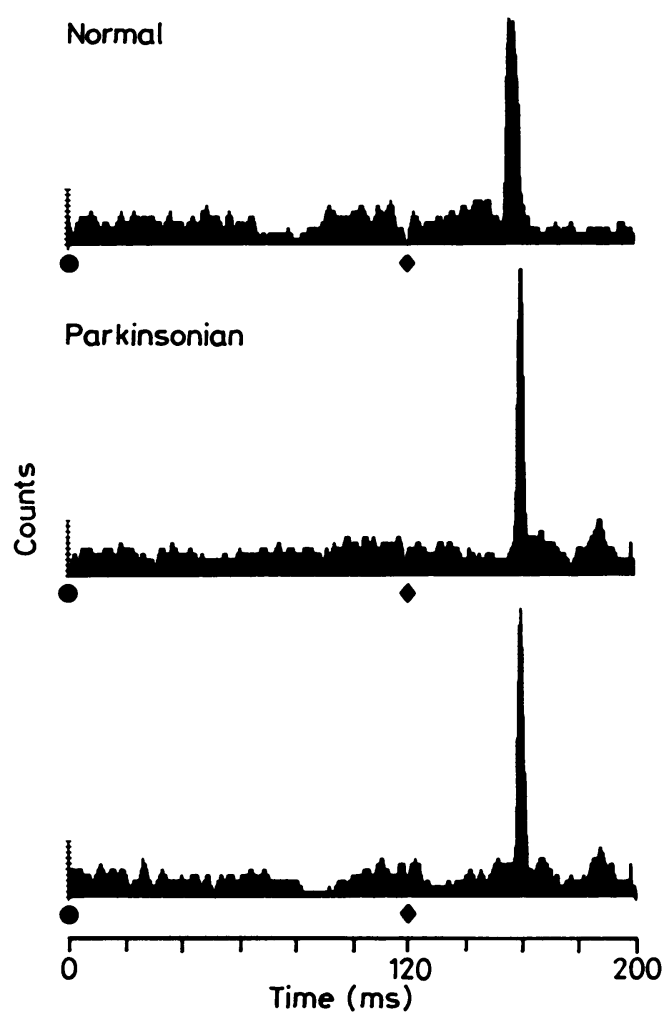

Fig 4 Stimulation of the common peroneal nerve (at 120 ms $(\bullet))$ below the threshold of the alpha motoneuron axons produces a short latency facilitation at $35 \mathrm{~ms}$ (corrected latency) and, in the Parkinsonian subject (second and third trace), a long latency facilitation at $63 \mathrm{~ms}$ (corrected latency) following the stimulus.

Stimulation of the deep peroneal nerve at the ankle at time zero (O) (at an intensity equal to the threshold of the alpha motoneuron axons to the extensor digitorum brevis muscle) produced an inhibition at $70 \mathrm{~ms}$ in the normal subject (top trace) and in the Parkinsonian subject (bottom trace).

Stimulation of the skin near the head of the fibula (middle trace at time zero (O)) produced no response. The stimulation intensity was the same as that used over the common peroneal nerve $(\bullet)$.

inhibition (fig 4). Electrical stimulation of the skin of the toes (applied with ring electrodes around the second and fifth toes) did facilitate tibialis anterior motor units but stimuli of 2.5 to 3 times the threshold of perception (which are painful) were necessary for this effect.

The range of firing rates of the motor units during the recordings was $5 \cdot 1-10 \cdot 4 \mathrm{~Hz}$ (mean $7 \cdot 3 \mathrm{~Hz}$ ) for the normal subjects and 6.3-10.6 Hz (mean $6.5 \mathrm{~Hz}$ ) for the subjects with Parkinson's disease. There was no correlation (either positive or negative) between the magnitudes of the short latency and the long latency responses. The long latency responses were also observed in first order peristimulus time histograms and were not, therefore, the result of double discharges of the motor unit.

\section{Discussion}

We observed short latency facilitation (onset 27-37 $\mathrm{ms}$ ) of tibialis anterior motor units following peroneal nerve stimulation. This facilitation likely represents the "monosynaptic" action of primary spindle afferents because: (a) it occurs with stimulation of muscle nerves well below the threshold of the alpha motoneuron axons, (b) the facilitation is seen only in the homonymous muscle or close synergists, ${ }^{20}$ (c) a similar facilitation of comparable latency follows tendon taps, ${ }^{21}$ (d) the effect is suppressed by muscle vibration, ${ }^{20}$ and (e) the estimated rise time of the underlying EPSP is short. ${ }^{22}$

We also recorded long latency (onset $50-70 \mathrm{~ms}$ ) facilitation of tibialis anterior motor units following electrical stimulation of the peroneal nerve. What can be deduced about the receptors and mechanisms of this response? The threshold of the responsible afferents was well below the threshold of the alpha motoneuron axons and was similar to that of the presumed group I afferents responsible for the short latency response. Electrical stimulation of cutaneous afferents, either near the head of the fibula or in the distribution of the peroneal nerve, failed to produce an appropriately timed facilitatory effect. Thus the long latency response appears to be generated by large, fast conducting afferents other than cutaneous afferents. A similar conclusion was reached by Iles ${ }^{23}$ who observed both early and late responses of similar latencies in recordings of surface EMG over tibialis anterior following electrical stimulation of the peroneal nerve, ramp stretch of the anterior tibial muscles and taps to the tibialis anterior tendon.

The methods in this study allow for more specific conclusions on the mechanism of the long latency response recorded here. Since electrical stimulation produces only a single afferent volley in a peripheral nerve $^{24}$ the long latency response in this study cannot be attributed to repetitive firing of primary afferents. ${ }^{25-28}$ (It is remotely possible that the volley passing antidromically in large afferents could result in a resurgence of impulses after a silent period. However, the lengths of the various afferents from the point of stimulation to the individual muscle receptors is variable making such synchronisation unlikely.) We observed both the short latency and long latency responses in the same tibialis anterior motor unit. The long latency responses therefore do not arise from two different subpopulations of motor units. ${ }^{2930} \mathrm{~A}$ double discharge of motoneurons ${ }^{31}$ cannot account for the long latency response because it was estab- 
lished (from first order peristimulus time histograms) that the motor unit did not fire twice in response to a single stimulus. The reactivation of peripheral receptors (for example as a consequence of the initial reflex response) is also an unlikely explanation for the long latency response for two reasons: (a) The $25 \mathrm{~ms}$ delay between the two responses is shorter than the monosynaptic reflex loop time and (b) the size of the long latency response was not, in any way, dependent on the size of the short latency response. The present findings thus lead to the conclusion that the responses arise from fast conducting, non-cutaneous afferents and that the "extra time" for the long latency response was taken up within the central nervous system presumably in a polysynaptic pathway. ${ }^{24-732-35}$

Fast conducting, non-cutaneous afferents may not be the only afferents that can give rise to long latency responses. In the upper extremity long latency responses have been observed following electrical stimulation of low threshold afferents in purely cutaneous nerves. ${ }^{36-41}$ In the lower extremity, however, long latency responses have not been consistently demonstrated following electrical stimulation of low threshold cutaneous afferents although long latency facilitation of flexor muscles may follow stimulation of high threshold afferents. For example Choa et $a l^{42}$ reported that electrical stimuli to the second toe "just below the pain threshold" produced a "short latency" increase in surface EMG over tibialis anterior followed 26-34 ms later by a later facilitation. The actual laencies of these responses were not reported. Iles ${ }^{23}$ reported that electrical stimulation of the distal plantar surface of the foot (intensity not reported) elicited responses in the pretibial muscles with a minimum latency of $70 \mathrm{~ms}$. Ashby et $\mathrm{al}^{\mathbf{4 3}}$ using painful stimuli to the second and fifth toes ( 3 to 4 times the threshold of perception) found facilitation of tibialis anterior motor units with a mean latency of $80 \mathrm{~ms}$ (range 69-97 ms) which was sometimes followed by a later facilitation with a mean latency of $99 \mathrm{~ms}$ (range 83-127 ms). Thus stimulation of small, high threshold cutaneous afferents also produces late facilitation of tibialis anterior motor units but these afferents are unlikely to mediate the responses demonstrated in this study following low intensity stimulation of the common peroneal nerve.

It is not implicit that the long latency responses to electrical stimulation of afferents and to limb perturbation share the same mechanisms. However, the long latency pathway from the large non muscle afferents observed in this study would be capable of contributing to the long latency response to limb perturbation since the receptors of large muscle afferents (for example Ia afferents) would also be excited by muscle stretch.
Explanation for the exaggerated long latency response in Parkinsonian subjects

We found that the long latency responses occurred in a greater proportion of patients with Parkinson's disease than in normal subjects. This cannot be attributed to an increase in the excitability of alpha motor neurons. Changes of firing probability of individual motoneurons that are discharging regularly reflect subthreshold events in those motoneurons. ${ }^{22} 44$ There was no parallel increase in the short latency period of facilitation, and the firing rate of the motor units was not higher in the Parkinsonian patients. Tatton et $\mathrm{al}^{7}$ reached a similar conclusion regarding the long latency response to limb perturbation (M2) by showing that the M2 (and not the M1) was increased in Parkinsonian patients even when the background level of muscle activity was matched by normal controls.

It is unlikely that different populations of motor units were sampled in the two groups since in both groups the observations were made on single motor units which were among the first to be recruited and which showed sustained firing for at least 10 minutes. In any case the muscle and cutaneous afferent projections to tibialis anterior motor units in man differ little with recruitment threshold. ${ }^{45}$

Nor can the exaggerated long latency response in the present study be explained by an increase in fusimotor drive or spindle sensitivity. Electrical stimulation of spindle afferents bypasses the effects of such changes in spindle excitability and spindle afferent discharges in Parkinsonian subjects are considered to be similar to those of normal subjects maintaining an equivalent muscle contraction. ${ }^{46}$ Thus it appears that an increased transmission in a polysynaptic pathway from large muscle afferents to motoneurons is the most plausible explanation for the increased long latency responses that we observed in Parkinsonian patients. This, of course, does not exclude additional mechanisms from contributing to the long latency response to muscle stretch.

This work was supported by a grant from the Medical Research Council of Canada (No MA6727, PA) and a studentship from the Ontario Ministry of Health (JPH).

We thank Dr J Rochon for statistical advice, Mary Cairoli for help preparing the manuscript, and $\mathrm{Dr}$ P B C Matthews for commenting on the manuscript.

\section{References}

1 Hammond PH. Involuntary activity in biceps following sudden application of velocity to the abducted forearm. J Physiol [Lond] 1954;127:23-25P.

2 Lee RG, Tatton WG. Motor responses to sudden limb displace- 
ments in primates with specific CNS lesions and in human patients with motor system disorders. Can J Neurol Sci 1975;2:285-92.

3 Hammond PH. An experimental study of servo actions in human muscular control. Proc III Int Conf Med Electron. Inst of Electrical Engineering. London 1960:190-9.

4 Marsden CD, Merton PA, Morton HB. Servo action in human voluntary movement. Nature 1972;238:140-3.

5 Desmedt JE (ed) Progress in Clinical Neurophysiology, vol 4: Cerebral Motor Control in Man: Long Loop Mechanisms. Basel: Karger, 1978.

6 Wiesendanger M, Miles T. Ascending pathway of low theshold muscle afferents to the cerebral cortex and its possible role in motor control. Physiol Rev 1982;62:1234-70.

7 Tatton WG, Eastman MJ, Bedingham W, Verrier MC, Bruce IC. Defective utilization of sensory input as the basis for bradykinesia, rigidity and decreased movement repertoire in Parkinson's disease: A hypothesis. Can J Neurol Sci 1984;11:136-43.

8 Matthews PBC. Evidence from the use of vibration that the human long latency stretch reflex depends upon spindle secondary afferents. J Physiol [Lond] 1984;348:383-415.

9 Cody FWJ, MacDermott N, Matthews PBC, Richardson HC. Observations on the genesis of the stretch reflex in Parkinson's disease. Brain 1986;109:229-49.

10 Gasser HS, Erlanger J. The role played by the size of the constituent fibers in nerve trunk in determining the form of its action potential wave. Am J Physiol 1927;80:522-47.

11 Rosenfalck A, Buchtal F. Sensory potentials for electrical and tactile stimuli. In: Desmedt JE, ed. New Developments in Electromyography and Clinical Neurophysiology Basel: Karger 1973;2:45-51.

12 Mortimer JA, Webster DD. Relationships between quantitative measures of rigidity and tremor and the electromyographic response to load perturbations in unselected normal subjects and Parkinsonian patients. In: Desmedt JE, ed. Cerebral Motor Control in Man: Long loop Mechanisms. Basel: Karger, Progress in Clinical Neurophysiology 1978;4:342-60.

13 Chan CWY, Kearney RE, Melvill Jones G. Tibialis anterior response to sudden ankle displacements in normal and Parkinsonian subjects. Brain Res 1979;173:303-14.

14 Rothwell JC, Obeso JA, Traub MM, Marsden CD. The behavior of the long latency stretch reflex in patients with Parkinson's disease. J Neurol Neurosurg Psychiatry 1983;46:35-44.

15 Lee RG, Murphy JT, Tatton WG. Long latency myotatic reflexes in man: Mechanisms, functional significance and change in patients with Parkinson's disease or hemiplegia. In: Desmedt JE, ed. Motor Control Mechanisms in Health and Disease. New York: Raven Press, 1983:489-508.

16 Berardelli A, Sabra AF, Hallett M. Physiological mechanisms of rigidity in Parkinson's disease. J Neurol Neurosurg Psychiatry 1983;46:45-53.

17 Struppler A, Lehman-Horn F, Klein W, Lucking CH, Deuschl G. Effect of stereoencephalotomy on long latency EMG responses and motor control of arm movements in Parkinson's syndrome. In: Hassler RG, Christ JF, eds. Advances in Neurology. New York: Raven Press, 1984;40:437-45.

18 Tatton WG, Bedingham W, Verrier MC, Blair RDG. Characteristic alterations in responses to imposed wrist displacements in Parkinsonian rigidity and dystonia musculorum deformans. Can J Neurol Sci 1984;11:281-7.

19 Scholz E, Diener HC, Noth J, Friedemann H, Dichgans J. Medium and long latency EMG responses in leg muscles: Parkinson's disease. J Neurol Neurosurg Psychiatry 1987;50:66-70.

20 Mao CC, Ashby P, Wang M, McCrea D. Synaptic connections from large muscle afferents to the motoneurons of various leg muscles in man. Exp Brain Res 1984;56:341-50.

21 Birnbaum A, Ashby P. Postsynaptic potentials in individual soleus motoneurons in man produced by achilles tendon taps and electrical stimulation of tibial nerve. Electroencephalogr Clin Neurophysiol 1982;54:469-71.

22 Ashby P, Zilm D. Characteristics of postsynaptic potentials pro- duced by single human motoneurons by homonymous group I volleys. Exp Brain Res 1982;47:41-8.

23 Iles JF. Responses in human pretibial muscles to sudden stretch and to nerve stimulation. Exp Brain Res 1977;30:451-70.

24 Burke D, Gandevia C, McKeon B. The afferent volleys responsible for spinal proprioceptive reflexes in man. J Physiol [Lond] 1983;339:535-52.

25 Hagbarth KE, Hagglund JV, Wallin EU, Young RR. Grouped spindle and electromyographic responses to abrupt wrist extension movements in man. $J$ Physiol [Lond] 1981;312:81-96.

26 Eklund G, Hagbarth KE, Hagglund KV, Wallin EU. Mechanical oscillations contributing to the segmentation of the reflex electromyogram response to stretching human muscles. $J$ Physiol [Lond] 1982;326:65-77.

27 Eklund G, Hagbarth KE, Hagglund KV, Wallin EU. The 'late' reflex responses to muscle stretch: The 'resonance hypothesis' versus the 'long-loop hypothesis'. J Physiol [Lond] 1982;326:79-90.

28 Berardelli A, Hallett M, Kaufman C, Fine E, Berenberg W, Simon SR. Stretch reflexes of triceps surae in normal man. $J$ Neurol Neurosurg Psychiatry 1982;45:513-25.

29 Bawa P, Tatton WG. Motor unit responses in muscles stretched by imposed displacements of the monkey wrist. Exp Brain Res 1979;37:417-37.

30 Calancie B, Bawa P. Firing patterns of human flexor carpi radialis motor units during the stretch reflex. $J$ Neurophysiol 1985;53:1179-93.

31 Lee RG, Tatton WG. Long latency reflexes to imposed displacements of the human wrist: dependence on duration of movement. Exp Brain Res 1982;45:207-16.

32 Phillips CG. Motor apparatus of baboon's hand. Proc $R$ Soc Lond [Biol] 1969;173:141-74.

33 Marsden CD, Merton PA, Morton HB. The sensory mechanism of servo action in human muscle. $J$ Physiol [Lond] 1977;265:521-35.

34 Evarts EV. Motor cortex reflexes associated with learned movements. Science 1973;179:501-3.

35 Noth J, Podoll K, Friedemann HH. Long loop reflexes in small hand muscles studied in normal subjects and in patients with Huntingdons disease. Brain 1985;108:65-80.

36 Conrad B, Aschoff JC. Effects of voluntary isometric and isotonic activity on late transcortical reflex components in normal subjects and hemiparetic patients. Electroencephalogr Clin Neurophysiol 1977;42:107-16.

37 Stanley EF. Reflexes evoked in human thenar muscles during voluntary activity and their conduction pathways. J Neurol Neurosurg Psychiatry 1978;41:1016-23.

38 Jenner JR, Stephens JA. Evidence for a transcortical cutaneous reflex response in man. $J$ Physiol [Lond] 1979;293:39-40P.

39 Garnett R, Stephens JA. The reflex responses of single motor units in human first dorsal interosseous muscle following cutaneous afferent stimulation. J Physiol [Lond] 1980;303:351-64.

40 Eisen A, Burton K, Larsen A, Hoirch M, Calne D. A new indirect method for measuring spinal conduction velocity in man. Electroencephalogr Clin Neurophysiol 1984;59:204-13.

41 Deuschl G, Schenck E, Lucking CH. Long-latency responses in human thenar muscles mediated by fast conducting muscle and cutaneous afferents. Neurosci Lett 1985;55:361-6.

42 Choa BHG, Stephens JA. Cutaneous reflex responses and central nervous lesions studied in the lower limb in man. J Physiol [Lond] 1982;328:23-24P.

43 Ashby P, Stalberg E, Winkler T, Hunter JP. Further observations on the depression of group Ia facilitation of motoneurons by vibration in man. Exp Brain Res 1987;69:1-6.

44 Fetz EE, Gustafsson B. Relation between shapes of post-synaptic potentials and changes in firing probability of cat motoneurones. J Physiol [Lond] 1983;341:387-410.

45 Ashby P, Hilton-Brown P, Stalberg E. Afferent projections to human tibialis anterior motor units at various levels of muscle contraction. Acta Physiol Scand (in press).

46 Burke D, Hagbarth K, Wallin BG. Reflex mechanisms in Parkinsonian rigidity. Scand J Rehabil Med 1977;9:15-23. 